\title{
Management of rheumatoid arthritis: consensus recommendations from the Hong Kong Society of Rheumatology
}

\author{
Chi Chiu Mok • Lai Shan Tam • Tak Hin Chan • \\ Gavin K. W. Lee • Edmund K. M. Li • \\ Hong Kong Society of Rheumatology
}

Received: 29 September 2010 / Accepted: 29 September 2010 /Published online: 3 November 2010

(C) The Author(s) 2010. This article is published with open access at Springerlink.com

\begin{abstract}
Given the recent availability of novel biologic agents for the treatment of rheumatoid arthritis (RA), the Hong Kong Society of Rheumatology has developed consensus recommendations on the management of RA, which aim at providing guidance to local physicians on appropriate, literature-based management of this condition, specifically on the indications and monitoring of the biologic disease-modifying anti-rheumatic drugs (DMARDs). The recommendations were developed using the European League Against Rheumatism (EULAR) recommendations for the management of early arthritis as a guide, along with local expert opinion. As significant joint damage occurs early in the course of RA, initiating therapy early is key to minimizing further damage and disability. Patients with serious disease or poor prognosis should receive early, aggressive therapy. Because of its good efficacy and safety profile, methotrexate is considered the standard first-line DMARD for most treatment-naïve RA patients. Patients with a suboptimal response to methotrexate monotherapy
\end{abstract}

C. C. Mok $(\bowtie)$

Department of Medicine, Tuen Mun Hospital,

Tuen Mun, Hong Kong

e-mail: ccmok2005@yahoo.com

L. S. Tam • E. K. M. Li

Department of Medicine \& Therapeutics, The Chinese University of Hong Kong, Prince of Wales Hospital,

Sha Tin, Hong Kong

T. H. Chan

Private practice,

Admiralty, Hong Kong

G. K. W. Lee

Department of Medicine, Union Hospital,

Sha Tin, Hong Kong should receive step-up (combination) therapy with either the synthetic or biologic DMARDs. In recent years, combinations of methotrexate with tocilizumab, abatacept, or rituximab have emerged as effective therapies in patients who are unresponsive to traditional DMARDs or the antitumor necrosis factor (TNF)- $\alpha$ agents. As biologic agents can increase the risk of infections such as tuberculosis and reactivation of viral hepatitis, screening for the presence of latent tuberculosis and chronic viral hepatitis carrier state is recommended before initiating therapy.

Keywords Hong Kong · Management · Recommendations · Rheumatoid arthritis

\section{Introduction}

Rheumatoid arthritis (RA) is a chronic, autoimmune, systemic, inflammatory disease mainly affecting the joints characterized by pain, swelling, and stiffness, resulting in progressive joint destruction, deformity, and loss of function. In addition to articular symptoms, other organ systems may also be involved. RA affects approximately $0.5 \%$ to $1 \%$ of the adult population in the developed world [1]. It is less prevalent in mainland China and in Hong Kong, with a reported prevalence of $0.37 \%$ and $0.35 \%$, respectively $[2,3]$.

Although the etiology of RA remains largely unknown, both genetic and nongenetic causes have been implicated. Inflammation is initially localized in the synovial lining where there is synovial cell proliferation (pannus formation) and infiltration by inflammatory cells. The pannus invades and destroys cartilage and bone, leading to irreversible joint destruction and deformity [4]. Erosions of the feet joints on extremity magnetic resonance imaging 
(MRI) are found in up to $91 \%$ of patients early in the course of the disease [5]. Therefore, early diagnosis and treatment are crucial for preventing further joint damage. Currently, the classification of RA is based on the 1987 American College of Rheumatology (ACR) clinical classification criteria using history, physical examination, and laboratory and radiographic findings [6]; this set of criteria has been criticized for lack of sensitivity in early disease. A new set of joint ACR-European League Against Rheumatism (EULAR) criteria for RA classification has recently been published [7].

The goals of treatment of RA are to alleviate symptoms, slow or stop disease progression, and reduce disability. The current RA treatment armamentarium comprises both synthetic and biologic disease-modifying anti-rheumatic drugs (DMARDs).

In 2005, the Hong Kong Society of Rheumatology (HKSR) published consensus recommendations on the use of anti-tumor necrosis factor (TNF)- $\alpha$ agents in the treatment of RA, ankylosing spondylitis, and psoriatic arthritis [8]. However, consensus recommendations on overall RA management had yet to be developed. Given the availability of newer biologic agents for RA treatment, the HKSR initiated the development of these consensus recommendations, which are aimed at providing guidance to Hong Kong physicians on appropriate, literature-based management of this condition, specifically on the indications and monitoring of the novel biologic DMARDs.

\section{Methods}

The consensus recommendations were developed using the EULAR recommendations for the management of early arthritis [9] as a guide, along with local expert opinion. Clinical evidence supporting these recommendations were categorized as to level of evidence based on the classification system in Table 1.

\section{Results}

Panel recommendations on RA management

Recommendation 1: General principles

Early RA treatment improves the rate of clinical response and ultimate outcome. Early, aggressive therapy is required for patients with serious disease and/or poor prognostic factors. Treatment must be individualized, based on physicians' and patients' preference, and medical contraindications, among others.
Evidence from published clinical trials shows better outcomes in early arthritis when treatment is initiated early; considerably more radiographic damage occurs when therapy is delayed (category A) [9-11]. In patients with more severe disease, it is important to achieve and maintain low disease activity as early as possible to prevent structural damage, thus necessitating a more intense treatment approach. Clinical trial data show that initial intensive treatment produces better outcomes than monotherapy in early arthritis (category A) [9, 12-14]. However, it is important to bear in mind that, given the variety of available treatments and the heterogeneity of patients, the management strategy should ultimately be tailored to the individual patient, taking into account factors such as individual preferences, contraindications, and side effects.

Recommendation 2: Patient assessment

(a) Anti-cyclic citrullinated peptide (anti-CCP) antibody testing, ultrasound, and MRI may be utilized in the early diagnosis of RA. These tests are not recommended as routine tests but should be used for specific indications only.

Anti-CCP testing may help establish an early diagnosis in patients who do not fulfill the 1987 ACR criteria, or for atypical cases. The anti-CCP antibodies have been shown to be more specific than the rheumatoid factor (RF) for diagnosing RA and possibly better predict radiographic progression of joint erosion (category C) [15]; anti-CCP testing has been incorporated into the new EULAR classification criteria to enhance its specificity for early disease [7]. Ultrasound and MRI are suitable for early diagnosis of bony erosions in patients who do not fulfill the 1987 ACR criteria, or as a guide for joint aspiration and injection in difficult cases. Both these imaging techniques are more sensitive than radiography for detecting cartilage and bone abnormalities and can even identify earlier stages of the disease (category B) [16, 17]. However, despite their benefits in early diagnosis of RA, these imaging techniques and testing for anti-CCP antibodies are significantly more costly and, therefore, should not be used routinely for every patient who presents with joint symptoms.

(b) Disease Activity Score using 28 joint counts (DAS28) should be utilized in the assessment of RA disease activity. Clinicians should try to compute the DAS28 at regular intervals, preferably during each clinic visit.

High disease activity (HDA): DAS28 $>5.1$

Moderate disease activity (MDA): DAS2 $8=3.2-5.1$

Low disease activity (LDA): DAS28 $=2.6-3.2$

Remission: DAS28 $<2.6$ 
Table 1 Strength of clinical evidence
At least one RCT or meta-analyses of RCTs, or reviews if these contain category A references

At least one controlled trial without randomization or at least one other type of experimental study, or extrapolated recommendations from RCTs or meta-analyses

Non-experimental descriptive studies, such as comparative studies, correlational studies, and case-control studies, which are extrapolated from RCTs, non-randomized controlled studies, or other experimental studies

Category D

Expert committee reports or opinions or clinical experience of respected authorities.

Also includes all abstracts

$R C T$ randomized control trial

The DAS28 is a useful instrument in clinical practice for objectively evaluating disease progression and response to therapy (category B) [18]. It includes four variables: (1) number of tender joints from among 28 joints, (2) number of swollen joints from among 28 joints, (3) erythrocyte sedimentation rate (ESR), and (4) patient's assessment of general health status. C-reactive protein (CRP) may be used as an alternative to ESR in the calculation of the DAS28 score, using predetermined formulas (category B) [19]. The DAS28 score ranges from 0 to 9.4 and can be used to readily classify disease activity levels into high, moderate, low, and remission.

(c) Factors indicating an unfavorable prognosis of RA include chronic smoking, high titres of anti-CCP or RF, radiologic erosion at onset, positive family history, HDA, severe functional limitation, and extraarticular manifestations (e.g., rheumatoid nodules).

Several prognostic factors have been linked with a worse outcome in RA. Numerous reports exist of a relationship between smoking and increased severity of RA (category C) $[20,21]$. The presence of anti-CCP antibodies is a strong predictor of radiological damage and progression (category C) [22]. In addition, HDA at baseline [23], RF [23], radiologic damage at disease onset [24], and presence of extra-articular manifestations [25] are also predictors of poor outcome (category C). The ACR 2008 recommendations further confirm these prognostic factors as commonly used clinically important predictors of poor RA outcome [26].

(d) Clinicians should regularly assess the extent of their patients' disability and functional capacity. Possible assessment tools include the Health Assessment Questionnaire (HAQ) and the Medical Outcomes Study short-form health survey (SF-36).

Since improving disability, function, and health-related quality of life are important goals for patients, regular assessments of these should become an integral part of RA management. The commonly used assessment tools, the HAQ and SF-36, assess the impact of disease in terms of patient-centered outcomes [27]. The HAQ, the most commonly used health status measure, primarily determines functional disability, while the SF-36 assesses limitations in physical activities, as well as emotional status of patients.

\section{Recommendation 3: Treatment}

(a) The goal of treatment is disease remission (i.e., DAS28 $<2.6$ ), regardless of whether the patient has early or established RA. It should be emphasized that treatment of early RA results in better response rates and a higher probability of drug-free remission.

Since there is no cure for RA, remission has become the accepted treatment goal to arrest joint damage and reduce the likelihood of long-term disability (category B) [9, 11]. Clinical trials of both early [12-14] and established [28] RA have demonstrated better remission rates and radiographic progression with early intensive treatment than monotherapy or routine care (category A).

(b) Treatment with synthetic DMARDs should be initiated as soon as possible after a diagnosis of RA is made. DMARD-naïve patients should be started on methotrexate monotherapy. Methotrexate should be given for a duration of no less than 3 months at the maximally tolerated dose. Patients without poor prognostic factors (i.e., with no erosions, are RF-negative, with low CRP levels, or with low disease activity) or those who cannot tolerate methotrexate may receive other DMARDs, such as leflunomide, sulfasalazine, hydroxychloroquine, or injectable gold. Corticosteroids, given orally, intramuscularly, or intra-articularly, may be used as bridging therapy as appropriate. A combination of DMARDs, or methotrexate combined with an anti-TNF- $\alpha$ agent, may be considered in patients with very serious disease and poor prognostic factors. However, the cost-effectiveness of the latter approach has yet to be determined.

Several clinical trials have clearly established the shortand long-term efficacy and the relatively beneficial safety profile of methotrexate in RA (category A) $[9,29,30]$. 
Methotrexate is considered the "anchor drug," and there is widespread acceptance for its use as initial therapy in most RA patients (category A) [9, 31, 32]. Alternative first-line treatments include sulfasalazine, which shows similar efficacy to methotrexate, and hydroxychloroquine, which has very good tolerability among the DMARDs (category B) $[11,26,33]$. Combination treatment with two or more DMARDs, or of methotrexate and an anti-TNF- $\alpha$ agent, has been shown to confer greater efficacy than monotherapy and, thus, is appropriate for patients with serious disease or poor prognostic factors (category A) [9, 12, 13, 34-36]. However, the cost-effectiveness of first-line intervention with biologic agents in treatment-naïve patients remains uncertain (category C) [37].

(c) Suboptimal treatment response is defined as failure to achieve remission (i.e., DAS28<2.6) after 3 months of methotrexate at a dose of at least $15 \mathrm{mg} /$ week. Such patients (i.e., DAS28 $\geq 2.6$ despite methotrexate) should receive step-up therapy, i.e., combination therapy of methotrexate plus another agent: methotrexate plus leflunomide, methotrexate plus sulfasalazine plus hydroxychloroquine, or methotrexate plus a biologic agent.

For patients who continue to present with active disease despite methotrexate, addition of another conventional DMARD or biologic agent should be considered (category A) $[9,11,26]$. In one randomized, placebo-controlled trial, the addition of leflunomide to existing methotrexate therapy resulted in significant clinical benefit in patients with persistently active RA (category A) [38]; however, given the recent FDA report of fulminant hepatitis in leflunomide users, meticulous monitoring of liver function is warranted in patients administered this drug [39]. In another randomized trial, combination therapy with methotrexate, sulfasalazine, and hydroxychloroquine resulted in better remission rates than single treatment in early RA (category A) [40]. Similarly, other randomized controlled trials have demonstrated better clinical efficacy when TNF- $\alpha$ inhibitors (etanercept, adalimumab, and infliximab) were given concomitant with methotrexate, following inadequate response to methotrexate alone (category A) [41-43]. The ACR 2008 recommendations suggest a variety of dual and triple drug combinations, incorporating methotrexate, depending on the patient's level of disease activity, disease duration, and prognostic features (category B) [26].

(d) Patients who require methotrexate plus a biologic agent may be administered any one of the following combinations: methotrexate plus an anti-TNF- $\alpha$ agent, methotrexate plus tocilizumab, methotrexate plus abatacept, or methotrexate plus rituximab. The choice of biologic will depend on various factors, including patient's and physician's preferences, availability of funding, and medical history.

The value of the combination of methotrexate and antiTNF- $\alpha$ agents in improving radiographic, clinical, and functional outcomes is well established (category A) [12, $13,36,41-43]$. In recent years, several novel biologic drugs with different mechanisms of action have emerged as potential additions to rheumatologic pharmacotherapy. These include the interleukin (IL)-6 inhibitor tocilizumab, the selective T-cell co-stimulation modulator abatacept, and the chimeric, anti-CD20 monoclonal antibody rituximab. Several recent randomized, double-blind, placebocontrolled trials have demonstrated superior therapeutic efficacy when each of these agents was co-administered with methotrexate in RA patients [44-51].

Trials involving tocilizumab have shown decreased disease activity and better remission rates (category A) [44-46]. One trial showed tocilizumab monotherapy to be superior to methotrexate monotherapy in DMARD/methotrexate-naïve patients (category A) [47]; another demonstrated that tocilizumab with methotrexate delayed radiographic progression of structural joint damage significantly more than methotrexate alone in patients who respond inadequately to methotrexate (category A) [48]. A clinical trial using abatacept demonstrated improvements in arthritis signs and symptoms, physical function, and quality of life at 1 year [49], and inhibition of radiological progression for up to 2 years (category A) [50]. Another clinical trial of rituximab showed improvements in disease activity, fatigue, disability, and health-related quality of life (category A) [51].

(e) Anti-TNF $\alpha$ failure patients (failure of DAS28 to improve by 1.2 or $<5.1$ over 16 weeks) may be administered any one of the following: another antiTNF- $\alpha$ agent, tocilizumab, abatacept, or rituximab. There is less evidence to support the efficacy of rituximab in seronegative RA patients.

Despite their efficacy in RA, anti-TNF- $\alpha$ agents elicit an inadequate response in a substantial number of patients. In such patients, alternative biologic agents are recommended. Evidence shows that patients who are refractory to anti$\mathrm{TNF}-\alpha$ therapy gain significant clinical and functional benefits from tocilizumab [44], rituximab [51], or abatacept (category A) [52]. However, rituximab may not be equally efficacious in all RA patients. A recent pooled analysis of two-phase III rituximab trials has shown that patients who are seropositive (anti-RF and anti-CCP positive) are significantly more likely to achieve a clinical response than those who are seronegative (category A) [53]. These findings suggest that the serological status of patients should be taken into consideration when choosing these biologic agents. 
Recommendation 4: Safety considerations

(a) Prior to using a biologic agent, the clinician should screen the patient for both active and latent tuberculosis infection. Patients with active tuberculosis should be adequately treated with the standard regimen before reconsideration of biologic treatment. Patients who screen positive for latent tuberculosis infection (i.e., with a positive purified protein derivative (PPD) test, defined as an induration of $\geq 10 \mathrm{~mm}$ in diameter) should be given isoniazid treatment for 9 months. If the indication for biologic use is not urgent, isoniazid should be given for 4 weeks, to assess tolerability, before administration of the biologic agent. For patients who test PPD-negative, there is insufficient evidence to recommend annual retesting unless there is recent exposure to tuberculosis or the risk of transmission is high.

Numerous reports indicate an increased risk of developing active tuberculosis soon after initiating anti-TNF- $\alpha$ agents (category A) [54]. Furthermore, in patients with a past history of tuberculosis, abatacept treatment may reactivate the infection as it is known to compromise T-cell immunity. This has led to the recommendation for routine screening for active and latent tuberculosis infection whenever treatment with these biologic agents is considered (category D) [54, 55]. While an induration of $\geq 10 \mathrm{~mm}$ in diameter has been determined to be appropriate to signify a positive PPD test for patients with RA, a lower cut-off of $\geq 5 \mathrm{~mm}$ has been utilized to define latent tuberculosis in patients who are significantly immunocompromised, such as those with human immunodeficiency virus (HIV) infection or who are transplant recipients (category D) [55]. Patients with evidence of latent tuberculosis infection should receive prophylactic tuberculosis treatment with isoniazid for 9 months before commencing biologic agents (category B) [54, 55]. Rifampicin as monotherapy for 4 months is recommended for patients resistant to, or intolerant of, isoniazid, or for whom isoniazid is contraindicated (category D) [55].

(b) In addition, the hepatitis $\mathrm{B}$ and $\mathrm{C}$ status of patients should be screened. Chronic carriage of hepatitis $\mathrm{B}$ and $\mathrm{C}$ virus (HBV and $\mathrm{HCV}$, respectively) is a relative contraindication for the use of antiTNF- $\alpha$ agents. Active hepatitis has to be excluded and baseline HBV DNA or HCV RNA levels should be checked for chronic carriers of HBV and HCV. Appropriate antiviral therapy, as determined by the co-managing hepatologist, is indicated. Patients should be warned of the risk of fulminant hepatitis reactivation. Rituximab is contraindicated in chronic hepatitis B or C carriers. There is little information regarding the safety of tocilizumab and abatacept in chronic viral hepatitis carriers.
Another important safety consideration when making therapeutic decisions with biologics is hepatitis B and C status. The anti-TNF- $\alpha$ agents are relatively contraindicated in carriers of $\mathrm{HBV}$ and $\mathrm{HCV}$ because of reports of viral reactivation, which can lead to serious complications (category B) $[26,56,57]$. If there are no alternatives, patients should be warned of the risk of serious hepatitis reactivation prior to administration of an anti-TNF- $\alpha$ agent. In clinical trials of hemic malignancies, rituximab has been shown to reactivate occult hepatitis B (i.e., HBsAg-negative but anti-HBc-IgGpositive) $[58,59]$; it is, therefore, contraindicated in chronic hepatitis B carriers and in patients with past hepatitis B infection. Hence, all candidate patients for these drugs should be screened for HBV and HCV infections before commencing treatment. In particular, the status of both HBsAg and anti$\mathrm{HBc}-\mathrm{IgG}$ should be determined before rituximab treatment. There is insufficient information on the safety of tocilizumab and abatacept in chronic viral hepatitis carriers.

(c) History of solid tumor is not a contraindication for use of anti-TNF- $\alpha$ agents if there is no recurrence in the past 5 years. Anti-TNF- $\alpha$ agents should be avoided in patients with a history of lymphoproliferative disorders.

Although etanercept has been associated with an increased incidence of solid malignancies in one clinical trial (category A) [60], anti-TNF- $\alpha$ therapy is generally not associated with an increased occurrence of solid tumors. According to a Swedish population-based study, the relative risks of solid cancers in anti-TNF- $\alpha$ treated patients were similar to those of other RA patients (category C) [61]. Hence, anti-TNF- $\alpha$ agents are not contraindicated in patients with solid tumor history if there is no recurrence in the past 5 years. However, they should be avoided in patients with prior lymphoproliferative disorders because of significantly increased risk of lymphomas (category C) [26, 62].

(d) Use of anti-TNF- $\alpha$ agents is contraindicated in patients with severe heart failure, demyelinating disorders, or lupus-like features.

Treatment of moderate-to-severe heart failure patients with anti-TNF- $\alpha$ agents has been associated with either no clinical benefit [63] or worsening of heart failure outcomes [64] (category A). Furthermore, these agents are known to induce autoimmune diseases such as demyelinating disorders and lupus and, as such, should be avoided in patients with these underlying conditions (category B) $[26,65]$.

(e) Live attenuated vaccines are not recommended for patients being treated with biologic agents. Killed vaccines (e.g., influenza vaccine, pneumococcal vaccine), if required, should be given prior to administration of biologic agent. 
Because the level of immune response to vaccinations may be impaired, live vaccines are contraindicated during biologic therapy (category D) [26]. Alternatively, inactivated vaccines can be safely administered, typically at least 2 to 4 weeks, before initiating biologic therapy.

(f) Patients on biologic agents should be closely monitored for side effects.

Patients should be very closely monitored for infective complications, including opportunistic infections.

Patients should be monitored for symptoms of tuberculosis infection, both within and outside the respiratory system. Chest X-ray should be performed every 3 months during the first year of therapy and annually thereafter, or when the patient develops symptoms.

Complete blood count, renal/liver function tests, lymphocyte count (for rituximab), and neutrophil count (for tocilizumab) should be regularly checked.
Fasting lipid levels should be regularly surveyed (particularly for tocilizumab) and statins should be given whenever appropriate.

Look out for new neurological symptoms in patients administered rituximab.

Look out for gastrointestinal symptoms in patients administered tocilizumab, especially those with a history of diverticulitis or intestinal ulceration.

Adverse events, especially serious adverse events, should be reported to the HKSR Biologics Registry.

Registries and databases have reported an increased risk of serious bacterial infections with the use of biologic DMARDs (category A) [66-68]. In particular, the rates of pneumonia and serious skin and soft tissue infections are increased. Once biologic therapy is initiated, patients should, therefore, undergo regular safety assessments. Chest X-rays should be performed to detect possible reactivation of latent tuberculosis. Laboratory testing, including lymphocyte count for rituximab and neutrophil count for tocilizumab, are warranted as treatment with each

Table 2 Panel recommendations on RA management—summary

Recommendation 1: General principles

Early RA treatment improves the outcome. Early, aggressive therapy is indicated for patients with serious disease and/or poor prognostic factors Recommendation 2: Patient assessment

(a) Anti-CCP antibody testing, ultrasound and MRI may be utilized to aid early diagnosis of RA but they are not recommended for routine use

(b) DAS 28 should be utilized in the assessment of RA disease activity. Clinicians should try to compute the DAS28 at regular intervals

(c) Factors indicating an unfavorable prognosis of RA include chronic smoking, high titres of anti-CCP or RF, radiologic erosion at onset, positive family history, HDA, severe functional limitation, and extra-articular manifestations (e.g., rheumatoid nodules)

(d) Clinicians should regularly assess the extent of their patients' disability and functional capacity

Recommendation 3: Treatment

(a) The goal of treatment is disease remission (i.e., DAS28<2.6)

(b) Treatment with synthetic DMARDs should be initiated as soon as possible after a diagnosis of RA is made. DMARD-naive patients should be started on MTX monotherapy. A combination of DMARDs, or MTX combined with an anti-TNF- $\alpha$ agent, may be considered in patients with very serious disease and poor prognostic factors

(c) Suboptimal treatment response is defined as failure to achieve remission after 3 months of MTX at its maximally tolerated dose. Such patients should receive step-up therapy, i.e., combination therapy of MTX plus another agent (e.g., LEF, SSz/HCQ, biologic agent)

(d) Patients who require MTX plus a biologic agent may be administered any one of the following combinations: MTX plus an anti-TNF- $\alpha$ agent, tocilizumab, abatacept, or rituximab

(e) Anti-TNF therapy failure patients may be administered another anti-TNF- $\alpha$ agent, tocilizumab, abatacept or rituximab

Recommendation 4: Safety considerations

(a) Prior to using a biologic agent, patients should be screened for tuberculosis infection. Patients with active tuberculosis should be adequately treated before reconsideration of biologic treatment. Patients who screen positive for latent tuberculosis infection receive isoniazid treatment for 9 months

(b) The hepatitis B and C status of patients should be screened. Active hepatitis has to be excluded and baseline HBV DNA or HCV RNA levels should be checked for chronic carriers. Appropriate antiviral therapy is indicated. Patients should be warned of the risk of fulminant hepatitis reactivation. Rituximab is contraindicated in chronic hepatitis $\mathrm{B}$ or $\mathrm{C}$ carriers

(c) Patients should be regularly monitored for side effects. Investigations such as chest radiograph, complete blood counts, lymphocyte count, liver and renal function tests, and lipid level should be assessed at regular intervals

Recommendation 5: Cardiovascular risk factors and bone mineral density

Patients with RA should be screened for risk factors for CV disease and for osteoporosis. Once detected, these conditions should be managed as appropriate 
of these agents is associated with rapid depletion of peripheral B-cells [51] and neutropenia [44-46, 69], respectively (category A). Treatment with biologic agents, particularly tocilizumab, can alter the serum lipid profile, resulting in increased low density lipoprotein (LDL), and total cholesterol levels (category B) [70]. Hence, it is important to monitor lipid levels and administer statin therapy, when required. Tocilizumab administration has been associated with bowel perforation and subsequent peritonitis [69] and, therefore, should be closely monitored in patients with a history of diverticulitis or intestinal ulceration (category B). Testing of laboratory safety parameters should be performed regularly.

Recommendation 5: Cardiovascular risk factors and bone mineral density

Patients with RA should be screened for risk factors for cardiovascular (CV) disease and for osteoporosis. Once detected, these conditions should be managed as appropriate.

RA patients are more prone to $\mathrm{CV}$ disease: the standardized incidence ratio of myocardial infarction and stroke is 1.5 to 1.7 times that of the incidence in the general population (category A) [71-74]. This is attributable to an increased prevalence of traditional $\mathrm{CV}$ risk factors and persistent elevation of inflammatory cytokines in this population. Early identification, adequate management, and ongoing monitoring of risk factors are necessary to reduce this excess CV risk. The latest EULAR recommendations for $\mathrm{CV}$ risk management in patients with $\mathrm{RA}$ and other forms of inflammatory arthritis states that the first principle of management is to assess and control all components of total $\mathrm{CV}$ risk, which includes providing appropriate, evidenced-based advice with regard to smoking, physical activity, diet, weight, and blood pressure, as well as aggressive suppression of the inflammatory process to further lower risk (category D) [75]. Similarly, RA patients are more likely to develop osteoporosis and fragility fractures (category A) [76]. Appropriate screening, monitoring and therapy for osteoporosis is deemed mandatory.

\section{Conclusion}

These recommendations by the HKSR summarize the latest evidence pertaining to RA management (Table 2), with a focus on the use of novel, biologic DMARDs. While methotrexate is still held up as the primary therapeutic option for most RA patients, new biologic agents currently available are recognized as effective and safe treatment modalities, particularly in patients with a suboptimal response to traditional DMARDs. Given that most of these biologics have only very recently come into use, and that they been associated with the development of infective and other complications, these recommendations emphasize the importance of vigilant monitoring for side effects, notably serious bacterial and viral infections, in patients administered these agents.

These recommendations will be reviewed periodically, in light of new published evidence and adverse event reports. As these recommendations evolve and gradually become more explicit, they will provide even more specific guidance to rheumatologists and other physicians who treat patients with RA, ultimately leading to improved clinical outcomes.

Acknowledgements The Hong Kong Society of Rheumatology would like to thank the following full members who were involved in the review of these consensus recommendations: Eric Yuk Tat Chan, Ka Ho Chan, Ka Man Chan, Ka Yan Helen Chan, Pui Shan Julia Chan, Yee Ki Chan, Shuk Yi Lucia Chau, Tak Cheong Cheung, Ho Yin Chung, Carmen Ho, Ling Yin Ho, Emily Kun, Lai Wa Kwok, Man Leung Kwok, Weng Ng Lao, Chak Sing Lau, Yu Lung Lau, Anthony Kai Yiu Lee, Ka Lai Lee, Kwok Fai, Tony Lee, Kwok Kei Lee, Man Yee Jolly Lee, Shui Shan Lee, Tsz Leung Lee, Tsz Yan, Samson Lee, Man Chi Leung, Moon Ho, Alexander Leung, Ying Ying Leung, Hor Ming Liu, Ming Chi Luk, Kai Yiu Ma, Lai Wo Mak, Mo Yin Mok, Kam Hung Daniel Ng, Woon Leung Ng, Chi Keung Sung, Ronald F. Tan, Shuk Kuen Sandy Tang, Chi Hung To, Hing Sum Tsui, John Chun Ming Wan, Man Choi Wan, Kong Chiu Wong, Shiu Man Jude Wong, Woon Sing Raymond Wong, Wai Shan Sandy Woo, Cheuk Wan Yim, Shirley King Yee Ying, Man Lung Yip, Ka Lung Carrel Yu, and Ka Yan Catherine Yuen.

Disclosures None

Open Access This article is distributed under the terms of the Creative Commons Attribution Noncommercial License which permits any noncommercial use, distribution, and reproduction in any medium, provided the original author(s) and source are credited.

\section{References}

1. Gabriel SE, Michaud K (2009) Epidemiological studies in incidence, prevalence, mortality, and comorbidity of the rheumatic diseases. Arthritis Res Ther 11:229

2. Lau E, Symmons D, Bankhead C et al (1993) Low prevalence of rheumatoid arthritis in the urbanized Chinese of Hong Kong. J Rheumatol 20:1133-1137

3. Xiang YJ, Dai SM (2009) Prevalence of rheumatic diseases and disability in China. Rheumatol Int 29:481-490

4. Choy EH, Panayi GS (2001) Cytokine pathways and joint inflammation in rheumatoid arthritis. N Engl J Med 344:907916

5. Olech E, Freeston JE, Conaghan PG et al (2008) Using extremity magnetic resonance imaging to assess and monitor early rheumatoid arthritis: the optimal joint combination to be scanned in clinical practice. J Rheumatol 35:580-583

6. Arnett FC, Edworthy SM, Bloch DA et al (1988) The American Rheumatism Association 1987 revised criteria for the classification of rheumatoid arthritis. Arthritis Rheum 31:315-324 
7. Aletaha D, Neogi T, Silman AJ et al (2010) 2010 Rheumatoid arthritis classification criteria: an American College of Rheumatology/European League against Rheumatism collaborative initiative. Ann Rheum Dis 69:1580-1588

8. Mok CC, for the working group on the use of TNF inhibitors for the treatment of rheumatic diseases in Hong Kong (2005) Consensus statements on the indications and monitoring of antitumor necrosis factor (TNF) therapy for rheumatic diseases in Hong Kong. Hong Kong Bull Rheum Dis 5:19-25

9. Combe B, Landewe R, Lukas C et al (2007) EULAR recommendations for the management of early arthritis: report of a task force of the European Standing Committee for International Clinical Studies Including Therapeutics (ESCISIT). Ann Rheum Dis 66:34-45

10. Lard LR, Visser H, Speyer I et al (2001) Early versus delayed treatment in patients with recent-onset rheumatoid arthritis: comparison of two cohorts who received different treatment strategies. Am J Med 111:446-451

11. O'Dell JR (2004) Therapeutic strategies for Rheumatoid arthritis. N Engl J Med 350:2591-2602

12. Breedveld FC, Weisman MH, Kavanaugh AF et al (2006) The PREMIER Study. A multicenter, randomized, double-blind clinical trial of combination therapy with adalimumab plus methotrexate versus methotrexate alone or adalimumab alone in patients with early, aggressive rheumatoid arthritis who had not had previous methotrexate therapy. Arthritis Rheum 54:26-37

13. St Clair EW, van der Heijde DM, Smolen JS et al (2004) Combination of infliximab and methotrexate therapy for early rheumatoid arthritis: a randomized, controlled trial. Arthritis Rheum 50:3432-3443

14. Grigor C, Capell H, Stirling A et al (2004) Effect of a treatment strategy of tight control for rheumatoid arthritis (the TICORA study): a single-blind randomised controlled trial. Lancet 364:263-269

15. Nishimura K, Sugiyama D, Kogata Y et al (2007) Meta-analysis: diagnostic accuracy of anti-cyclic citrullinated peptide antibody and rheumatoid factor for rheumatoid arthritis. Ann Intern Med 146:797-808

16. Wakefield RJ, Gibbon WW, Conaghan PG et al (2000) The value of sonography in the detection of bone erosions in patients with rheumatoid arthritis: a comparison with conventional radiography. Arthritis Rheum 43:2762-2770

17. Poleksic L, Zdravkovic D, Jablanovic D, Watt I, Bacic G (1993) Magnetic resonance imaging of bone destruction in rheumatoid arthritis: comparison with radiography. Skeletal Radiol 22:577-580

18. Fransen J, van Riel PL (2009) The disease activity score and the EULAR response criteria. Rheum Dis Clin North Am 35:745-757

19. University Medical Centre Nijmegen. DAS-SCORE.NL. Home of the DAS. Available at: http://www.das-score.nl/www.das-score.nl/. Accessed 1 June 2010.

20. Saag KG, Cerhan JR, Kolluri S, Ohashi K, Hunninghake GW, Schwartz DA (1997) Cigarette smoking and rheumatoid arthritis severity. Ann Rheum Dis 56:463-469

21. Masdottir B, Jónsson T, Manfredsdottir V, Víkingsson A, Brekkan A, Valdimarsson H (2000) Smoking, rheumatoid factor isotypes and severity of rheumatoid arthritis. Rheumatology (Oxford) 39:1202-1205

22. Forslind K, Ahlmén M, Eberhardt K, Hafström I, BARFOT Study Group (2004) Prediction of radiological outcome in early rheumatoid arthritis in clinical practice: role of antibodies to citrullinated peptides (anti-CCP). Ann Rheum Dis 63:1090-1095

23. Möttönen T, Paimela L, Leirisalo-Repo M, Kautiainen H, Ilonen J, Hannonen P (1998) Only high disease activity and positive rheumatoid factor indicate poor prognosis in patients with early rheumatoid arthritis treated with "sawtooth" strategy. Ann Rheum Dis 57:533-539
24. Richi P, Balsa A, Muñoz-Fernández S et al (2002) Factors related to radiological damage in 61 Spaniards with early rheumatoid arthritis. Ann Rheum Dis 61:270-272

25. Young A, Koduri G (2007) Extra-articular manifestations and complications of rheumatoid arthritis. Best Pract Res Clin Rheumatol 21:907-927

26. Saag KG, Teng GG, Patkar NM et al (2008) American College of Rheumatology 2008 recommendations for the use of nonbiologic and biologic disease-modifying antirheumatic drugs in rheumatoid arthritis. Arthritis Rheum 59:762-784

27. Lillegraven S, Kvien TK (2007) Measuring disability and quality of life in established rheumatoid arthritis. Best Pract Res Clin Rheumatol 21:827-840

28. van der Heijde D, Klareskog L, Boers M et al (2005) Comparison of different definitions to classify remission and sustained remission: 1 year TEMPO results. Ann Rheum Dis 64:1582-1587

29. Weinblatt ME, Coblyn JS, Fox DA et al (1985) Efficacy of lowdose methotrexate in rheumatoid arthritis. N Engl J Med 312:818822

30. Weinblatt ME, Kaplan H, Germain BF et al (1994) Methotrexate in rheumatoid arthritis. A five-year prospective multicenter study. Arthritis Rheum 37:1492-1498

31. Pincus T, Yazici Y, Sokka T, Aletaha D, Smolen JS (2003) Methotrexate as the "anchor drug" for the treatment of early rheumatoid arthritis. Clin Exp Rheumatol 21:S179-S185

32. Mikuls TR, O'Dell JR (2000) The changing face of rheumatoid arthritis therapy: results of serial surveys. Arthritis Rheum 43:464-465

33. Felson DT, Anderson JJ, Meenan RF (1990) The comparative efficacy and toxicity of second-line drugs in rheumatoid arthritis: results of two metaanalyses. Arthritis Rheum 33:1449-1461

34. Boers M, Verhoeven AC, Markusse HM et al (1997) Randomized comparison of combined step-down prednisolone, methotrexate and sulphasalazine with sulphasalazine alone in early rheumatoid arthritis. Lancet 350:309-318

35. Landewe RB, Boers M, Verhoeven AC et al (2002) COBRA combination therapy in patients with early rheumatoid arthritis: long-term structural benefits of a brief intervention. Arthritis Rheum 46:347-356

36. Klareskog L, van der Heijde D, de Jager JP et al (2004) Therapeutic effect of the combination of etanercept and methotrexate compared with each treatment alone in patients with rheumatoid arthritis: double-blind randomised controlled trial. Lancet 363:675-681

37. Finckh A, Bansback N, Marra CA et al (2009) Treatment of very early rheumatoid arthritis with symptomatic therapy, diseasemodifying antirheumatic drugs, or biologic agents: a costeffectiveness analysis. Ann Intern Med 151:668-669

38. Kremer JM, Genovese MC, Cannon GW et al (2002) Concomitant leflunomide therapy in patients with active rheumatoid arthritis despite stable doses of methotrexate. A randomized, double-blind, placebo-controlled trial. Ann Intern Med 137:726-733

39. US Food and Drug Administration (FDA) Web site. FDA Drug Safety Communication: New boxed warning for severe liver injury with arthritis drug Arava (leflunomide). Available at: http://www.fda.gov/Drugs/DrugSafety/PostmarketDrugSafety InformationforPatientsandProviders/ucm 218679.htm. Accessed 31 July 2010.

40. Möttönen T, Hannonen P, Leirisalo-Repo $M$ et al (1999) Comparison of combination therapy with single-drug therapy in early rheumatoid arthritis: a randomised trial. The Lancet 353:1568-1573

41. Weinblatt ME, Kremer JM, Bankhurst AD et al (1999) A trial of etanercept, a recombinant tumor necrosis factor receptor:Fc fusion protein, in patients with rheumatoid arthritis receiving methotrexate. N Engl J Med 340:253-259 
42. Keystone EC, Kavanaugh AF, Sharp JT et al (2004) Radiographic, clinical, and functional outcomes of treatment with adalimumab (a human anti-tumor necrosis factor monoclonal antibody) in patients with active rheumatoid arthritis receiving concomitant methotrexate therapy: a randomized, placebo-controlled, 52-week trial. Arthritis Rheum 50:1400-1411

43. Maini RN, Breedveld FC, Kalden JR et al (2004) Sustained improvement over 2 years in physical function, structural damage, and signs and symptoms among patients with rheumatoid arthritis treated with infliximab and methotrexate. Arthritis Rheum 50:1051-1065

44. Emery P, Keystone E, Tony HP et al (2008) IL-6 receptor inhibition with tocilizumab improves treatment outcomes in patients with rheumatoid arthritis refractory to anti-tumour necrosis factor biologics: results from a 24-week multicentre randomised placebo-controlled trial. Ann Rheum Dis 67:15161523

45. Maini RN, Taylor PC, Szechinski J et al (2006) Double-blind randomized controlled clinical trial of the interleukin- 6 receptor antagonist, tocilizumab, in European patients with rheumatoid arthritis who had an incomplete response to methotrexate. Arthritis Rheum 54:2817-2829

46. Smolen JS, Beaulieu A, Rubbert-Roth A et al (2008) Effect of interleukin-6 receptor inhibition with tocilizumab in patients with rheumatoid arthritis (OPTION study): a double-blind, placebocontrolled, randomised trial. Lancet 371:987-997

47. Jones G, Sebba A, Gu J et al (2010) Comparison of tocilizumab monotherapy versus methotrexate monotherapy in patients with moderate to severe rheumatoid arthritis: the AMBITION study. Ann Rheum Dis 69:88-96

48. Kremer J, Fleischmann R, Halland A, et al. (2008) Tocilizumab inhibits structural joint damage in rheumatoid arthritis patients with an inadequate response to methotrexate: the LITHE study [abstract]. Ann Rheum Dis;58:abstr L14.

49. Kremer JM, Genant HK, Moreland LW et al (2006) Effects of abatacept in patients with methotrexate-resistant active rheumatoid arthritis: a randomized trial. Ann Intern Med 144:865876

50. Kremer JM, Genant HK, Moreland LW et al (2008) Results of a two-year followup study of patients with rheumatoid arthritis who received a combination of abatacept and methotrexate. Arthritis Rheum 58:953-963

51. Cohen SB, Emery P, Greenwald MW et al (2006) Rituximab for rheumatoid arthritis refractory to anti-tumor necrosis factor therapy: results of a multicenter, randomized, doubleblind, placebo-controlled, phase III trial evaluating primary efficacy and safety at 24 weeks. Arthritis Rheum 54:27932806

52. Genovese MC, Becker JC, Schiff M et al (2005) Abatacept for rheumatoid arthritis refractory to tumor necrosis factor alpha inhibition. N Engl J Med 353:1114-1123

53. Isaacs JD, Olech E, Tak PP et al (2009) Autoantibody-positive rheumatoid arthritis (RA) patients (pts) have enhanced clinical response to rituximab (RTX) when compared with seronegative patients. Ann Rheum Dis 68(Suppl 3):442

54. Keane J (2005) TNF-blocking agents and tuberculosis: new drugs illuminate an old topic. Rheumatology 44:714-720

55. American Thoracic Society, Centers for Disease Control and Prevention (2000) This official statement of the American Thoracic Society was adopted by the ATS Board of Directors, July 1999. This is a Joint Statement of the American Thoracic Society (ATS) and the Centers for Disease Control and Prevention (CDC). This statement was endorsed by the Council of the Infectious Diseases Society of America (IDSA), September 1999, and the sections of this statement. Am J Respir Crit Care Med 161:S221-S247
56. Calabrese LH, Zein NN, Vassilopoulos D (2006) Hepatitis B virus (HBV) reactivation with immunosuppressive therapy in rheumatic diseases: assessment and preventive strategies. Ann Rheum Dis 65:983-989

57. Nathan DM, Angus PW, Gibson PR (2006) Hepatitis B and C virus infections and anti-tumor necrosis factor- $\alpha$ therapy: Guidelines for clinical approach. J Gastroenterol Hepatol 21:1366-1371

58. Matsue K, Kimura SI, Takanashi Y, et al. (2010) Reactivation of hepatitis $\mathrm{B}$ virus after rituximab-containing treatment in patients with CD20-positive B-cell lymphoma. Cancer. [Epub ahead of print]

59. Ji D, Cao J, Hong X, et al. (2010) Low incidence of hepatitis $B$ virus reactivation during chemotherapy among diffuse large B-cell lymphoma patients who are $\mathrm{HBsAg-negative/HBcAb-}$ positive: a multicenter retrospective study. Eur J Haematol. [Epub ahead of print]

60. Stone JH, Holbrook JT, Marriott MA et al (2006) Solid malignancies among patients in the Wegener's Granulomatosis Etanercept Trial. Arthritis Rheum 54:1608-1618

61. Askling J, Fored CM, Brandt L et al (2005) Risks of solid cancers in patients with rheumatoid arthritis and after treatment with tumour necrosis factor antagonists. Ann Rheum Dis 64:14211426

62. Geborek P, Bladström A, Turesson C et al (2005) Tumour necrosis factor blockers do not increase overall tumour risk in patients with rheumatoid arthritis, but may be associated with an increased risk of lymphomas. Ann Rheum Dis 64:699-703

63. Mann DL, McMurray JJ, Packer M et al (2004) Targeted anticytokine therapy in patients with chronic heart failure: results of the Randomized Etanercept Worldwide Evaluation (RENEWAL). Circulation 109:1594-1602

64. Chung ES, Packer M, Lo KH, Fasanmade AA (2003) AntiTNF Therapy Against Congestive Heart Failure Investigators. Randomized, double-blind, placebo-controlled, pilot trial of infliximab, a chimeric monoclonal antibody to tumor necrosis factor-alpha, in patients with moderate-to-severe heart failure: results of the anti-TNF Therapy Against Congestive Heart Failure (ATTACH) trial. Circulation 107:31333140

65. Ramos-Casals M, Roberto-Perez-Alvarez, Diaz-Lagares C, Cuadrado MJ, Khamashta MA, BIOGEAS Study Group (2010) Autoimmune diseases induced by biologic agents: a double-edged sword? Autoimmun Rev 9:188-193

66. Galloway JB, Hyrich KL, Mercer LK, et al. (2010) Anti-TNF therapy is associated with an increased risk of serious infections in patients with rheumatoid arthritis especially in the first 6 months of treatment: updated results from the British Society for Rheumatology Biologics Register with special emphasis on risks in the elderly. Rheumatology (Oxford). [Epub ahead of print]

67. Listing J, Strangfeld A, Kary S et al (2005) Infections in patients with rheumatoid arthritis treated with biologic agents. Arthritis Rheum 52:3403-3412

68. Curtis JR, Patkar N, Xie A et al (2007) Risk of serious bacterial infections among rheumatoid arthritis patients exposed to tumor necrosis factor antagonists. Arthritis Rheum $56: 1125-1133$

69. Koike R, Harigai M, Atsumi T et al (2009) Japan College of Rheumatology 2009 guidelines for the use of tocilizumab, a humanized anti-interleukin-6 receptor monoclonal antibody, in rheumatoid arthritis. Mod Rheumatol 19:351-357

70. Schimmel EK, Yazici Y (2009) Increased lipid levels but unchanged atherogenic index in rheumatoid arthritis patients treated with biologic disease modifying antirheumatic drugs: published experience. Clin Exp Rheumatol 27:446-451 
71. Han C, Robinson DW, Hackett MV et al (2006) Cardiovascular disease and risk factors in patients with rheumatoid arthritis, psoriatic arthritis and ankylosing spondylitis. J Rheumatol $33: 2167-2172$

72. Turesson C, Jarenros A, Jacobsson L (2004) Increased incidence of cardiovascular disease in patients with rheumatoid arthritis: results from a community based study. Ann Rheum Dis 63:952-955

73. Solomon DH, Karlson EW, RImm EB et al (2003) Cardiovascular morbidity and mortality in women diagnosed with rheumatoid arthritis. Circulation 107:1303-1307
74. Wolfe F, Freundlich B, Straus WL (2003) Increase in cardiovascular and cerebrovascular disease prevalence in rheumatoid arthritis. J Rheumatol 30:36-40

75. Peters MJ, Symmons DP, McCarey D et al (2010) EULAR evidence-based recommendations for cardiovascular risk management in patients with rheumatoid arthritis and other forms of inflammatory arthritis. Ann Rheum Dis 69:325331

76. Deane K (2006) Increased prevalence translates into increased fractures-Osteoporosis in RA: a common comorbidity. J Musculoskel Med 23:838-844 